\title{
Vibrio viscosus in farmed Atlantic salmon Salmo salar in Scotland: field and experimental observations
}

\author{
D. W. Bruno*, J. Griffiths, J. Petrie, T. S. Hastings \\ FRS Marine Laboratory, PO Box 101, Victoria Road, Aberdeen AB11 9DB, Scotland
}

\begin{abstract}
Winter mortality occurred in market-sized (2 to $3 \mathrm{~kg}$ ) Atlantic salmon Salmo salar reared in sea cages in Scottish waters. Many of the fish had skin ulcers. Internally prominent dark-brown petechiae or ecchymotic haemorrhage was observed. Splenomegaly was associated with congestion and widespread necrosis. A Vibrio sp. was isolated from internal organs. Biochemically isolates of the bacterium were similar to a previously described bacterium, Vibrio viscosus, recorded in a phenotypic study from farmed salmon in Norway. This work examines the occurrence of $V$. viscosus in marinereared Atlantic salmon for the first time in Scottish waters. An experimental study reproduced the field observations and Koch's postulates were fulfilled. The histopathology associated with natural infection was compared with that in laboratory-infected fish.
\end{abstract}

KEY WORDS: Atlantic salmon S Salmo salar - Vibrio viscosus Pathology - Experimental infection

\section{INTRODUCTION}

Bacterial infections involving Vibrio spp. occur among farmed and wild fish and are causes of significant mortality (Toranzo \& Barja 1993). Improved taxonomy and knowledge of fish disease have highlighted several new species of Vibrio as primary causes of infection, particularly from the marine environment. For example, 'Hitra disease' caused by Vibrio salmonicida (Egidius et al. 1986) was first reported in farmed Atlantic salmon Salmo salar in Norway by Egidius et al. (1981). Outbreaks have subsequently occurred in farmed Atlantic salmon in Scotland (Bruno et al. 1986). In 1980 a further Vibrio problem emerged for marine salmonid aquaculture in Norway and the term 'winter ulcers' was introduced during the 1990s (Lunder 1992, Salte et al. 1994). The term 'winter ulcers' reflects the lateral lesions found on infected fish (Salte et al. 1994). In Iceland, several Vibrio spp. have been isolated from farmed Atlantic salmon (Benediksdóttir et al. 1998), including some strains where the gross signs recorded were comparable with those of 'winter ulcers' condi-

·E-mail: brunodw@marlab.ac.uk tion in Norway. Experimental studies by Benediksdóttir \& Helgason (1997) and Benediksdóttir et al. (1997) have confirmed the presence of $V$ viscosus as an infectious agent of farmed Atlantic salmon in Iceland Several causes of winter ulcers were postulated (Salte et al. 1994), although work by Lunder (1992) and Lunder et al. (1995) demonstrated a Vibrio sp. as the causative agent. Currently, the name Vibrio viscosus has been proposed for the causative agent of this condition (Lunder 1992). The study reported here examines the occurrence of $V$, viscosus in marine-reared Atlantic salmon for the first time in Scottish waters. The histopathology associated with natural infection in farmed salmon is discussed and compared with that reproduced in laboratory-infected fish.

\section{MATERIALS AND METHODS}

Fish and bacterial isolation. Moribund market-sized Atlantic salmon Salmo salar (weight 2 to $3 \mathrm{~kg}$ ) were removed by netting from sea cages on the eastern side of the Shetland Isles, Scotland. Fish were anaesthetised in tricaine methanesulphonate (MS-222, Sigma, UK). 
At necropsy gross lesions were recorded without magnification. Inocula from field and laboratory-infected fish were taken from the kidney, spleen and liver for bacteriological investigation. Tissues were inoculated onto the following media; tryptone soya agar (TSA; Oxoid) $+2 \% \mathrm{NaCl}$, TSA $+\mathrm{NaCl}$ with $10 \%$ horse blood and modified Anacker and Ordals media (A\&O; Lorenzen 1993). All plates were incubated at $15^{\circ} \mathrm{C}$ and examined daily for up to $10 \mathrm{~d}$.

Light microscopy. Gills, kidney, heart, liver, spleen, brain, gut and pyloric caeca were dissected from farmed and laboratory-infected fish and samples fixed in $8 \%$ buffered formalin. Tissues were processed and sections stained for light microscopy with Harris' haematoxylin and eosin (H\&E), Giemsa and Gram.

Experimental infection. Atlantic salmon post smolts ( $150 \mathrm{~g}$ ) were moved from the Marine Laboratory's site at Aultbea, Ross-shire, to the Aberdeen aquarium and allowed to acclimatise for $3 \mathrm{wk}$. Two groups of $30 \mathrm{fish}$ were anaesthetised with MS-222. Each fish was injected intraperitoneally (i.p.) with a $0.1 \mathrm{ml}$ suspension of a 3 d culture of Vibrio viscosus (MT 1887) isolated from farm fish, to give an absorbance at $540 \mathrm{~nm}$ of 1.0 (group A) or 0.71 (group B) in phosphate buffered saline (PBS). This isolate was subcultured once before injection. Following injection, fish were placed according to dose into $1 \mathrm{~m}$ circular tanks to recover. Five control fish were marked intradermally with Alcian blue and added to each challenge group. Ten fish were injected with $0.1 \mathrm{ml}$ PBS and placed in an adjacent tank. Sea water was supplied to each tank at 320 to $350 \mathrm{l} \mathrm{h}^{-1}$ at ambient temperature $\left(6\right.$ to $8^{\circ} \mathrm{C}$ ). A commercial diet was fed throughout the study. All moribund individuals were sampled throughout the $28 \mathrm{~d}$ trial following anaesthesia. Moribund fish were considered as part of the overall mortality. The uminfected (controls) and remaining fish in each tank were sampled on completion of the study (Day 28).

Morphology and biochemical characteristics. Colony morphology was recorded and cultures subject to Gram staining, and oxidase and catalase testing. Further biochemical testing was carried out using API $20 \mathrm{E}$ and API $50 \mathrm{CH}$ test strips (bioMérieux, Hampshire, $\mathrm{UK}$ ) at $15^{\circ} \mathrm{C}$ and recorded after $72 \mathrm{~h}$ incubation. Isolates of Vibrio viscosus were tested with antibody agglutination kits for $V$. anguillarum and $V$. salmonicida (Bionor Mono, Skien, Norway). Antibiotic sensitivity was determined to amoxycillin, cotrimoxazole, oxolinic acid, oxytetracycline and the vibriostat agent $0 / 129$ using disc diffusion assays on Mueller Hinton agar (Difco, Surrey, UK) containing $2 \% \mathrm{NaCl}$ at $15^{\circ} \mathrm{C}$.

Mortality. Mortality data from all causes were collected from the affected fish farm at weekly intervals from October to January.

\section{RESULTS}

\section{Pathological signs}

Affected farmed fish were lethargic, dark in colour and showed gill pallor, and exophthalmos but with no haemorrhage in the eye chamber. Externally, circular or oval, epidermal ulcers were recorded on the scalecovered areas of most fish and ranged in diameter from 0.5 to $2.0 \mathrm{~cm}$ (Fig. 1). These ulcers were evident at

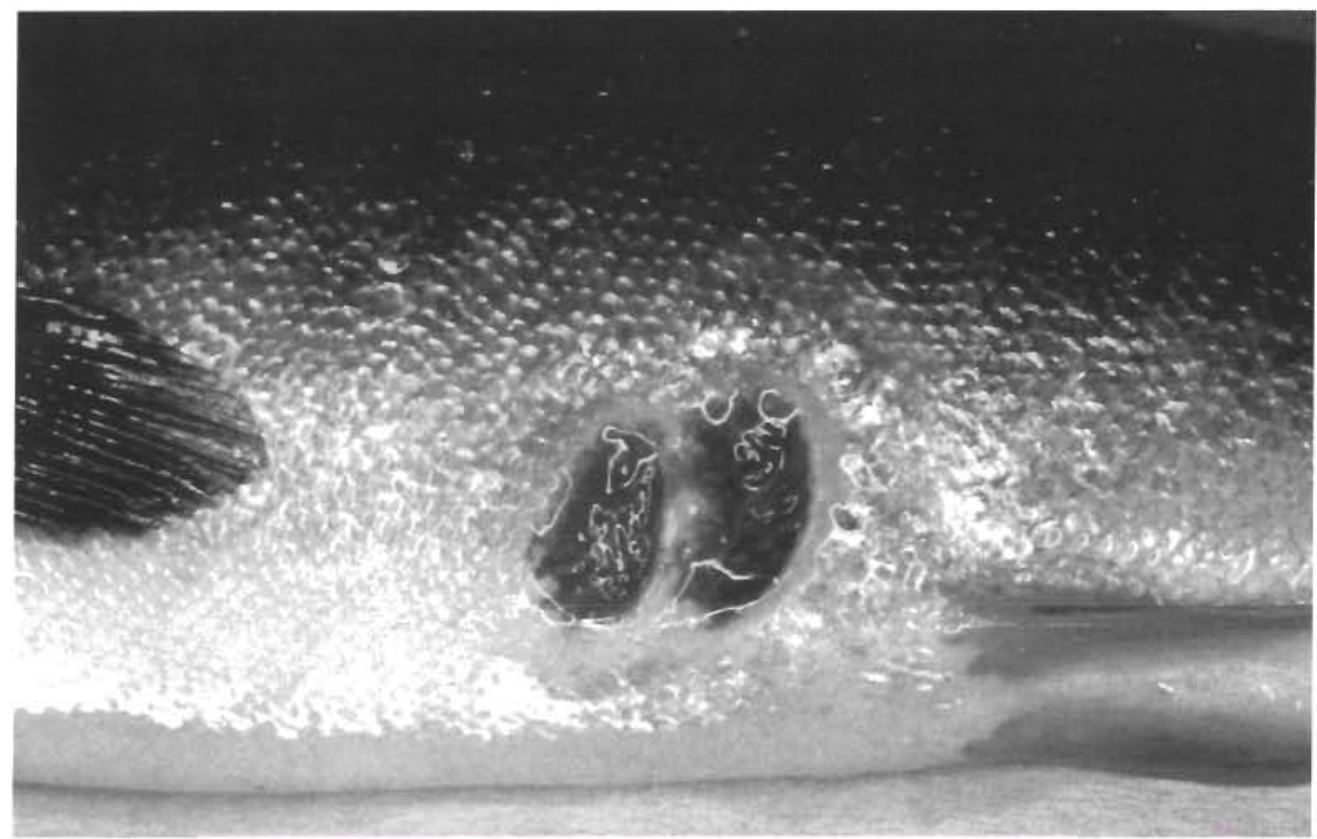

Fig. 1 Oval, epidermal lesions on Atlantic salmon Salmo salar naturally infected with Vibrio viscosus 
various sites over the body surface ranging from superficial to those extending beyond the stratum compactum exposing the musculature. Internally, the most noticeable feature was the presence of dark brown, almost black areas across the uncut surface of the normal or pale-coloured liver. In some cases this was confined to a few dark petechiae or ecchymotic haemorrhage $1 \mathrm{~mm}$ in diameter whereas in other fish approximately $80 \%$ of the surface was affected (Fig. 2). When cut, the dark areas were obvious throughout the tissue and mixed with yellow-brown liver tissue. Splenomegaly was common and in one fish the splenic membrane was rough, and the kidney slightly swollen. In several fish ascites was recorded within the abdominal cavity with a generalised haemorrhage. The stomach and gut were empty, suggesting the fish had stopped feeding. Adequate fat tissue was evident around the pyloric caeca. Most of the above signs were also recorded in moribund laboratory-infected fish with lesions on the body surface and internal haemorrhage, although generally the dark brown/black patches on the liver surface were smaller or sometimes absent.

\section{Mortality}

Mortality among the farmed salmon between October and January was $0.3,0.7,1.0$ and $0.8 \%$ respec- tively. In laboratory infection experiments, $4 \mathrm{~d}$ after receiving an i.p. injection mortality was recorded in group A (i.e. the high dose fish) and moribund fish were removed for examination up to Day 16. In group $B$ (i.e. the low dose fish) fish deaths wure first noted at $10 \mathrm{~d}$ post injection. After Day 15 no further moribund fish were removed from this group. All remaining fish were sampled on Day 28. The cumulative mortality in group $A$ was $46 \%$ and in group $B$ $20 \%$. No mortality was recorded in the non-infected, cohabiting fish or those held in an adjacent tank.

\section{Histopathology}

A moderate to marked congestion occurred throughout large areas of the liver forming large blood-filled cavities. There was little evidence of inflammation and the hepatocyte matrix was generally intact with only scattered single cell necrosis recorded. Minor skin ulcers showed some subepidermal infiltration, a lack of cellular reaction and some patchy necrosis. More severe lesions were associated with increased numbers of inflammatory cells and localised oedema. The spleen showed congestion with widespread necrosis resulting in the destruction of most of the tissue in moribund fish. Within each lesion a central focus of Gram-negative bacteria occurred with congestion and
Fig. 2. Gross lesion showing dark ecchymotic haemorrhage scattered throughout the liver from Atlantic salmon Salmo salar naturally infected by Vibrio viscosus

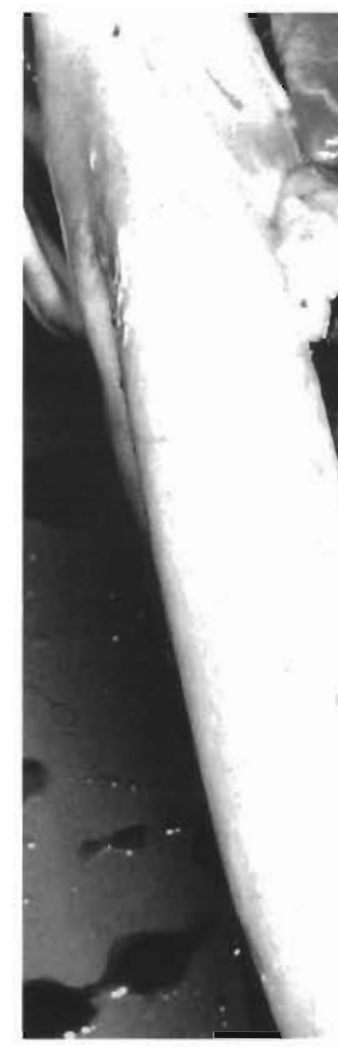

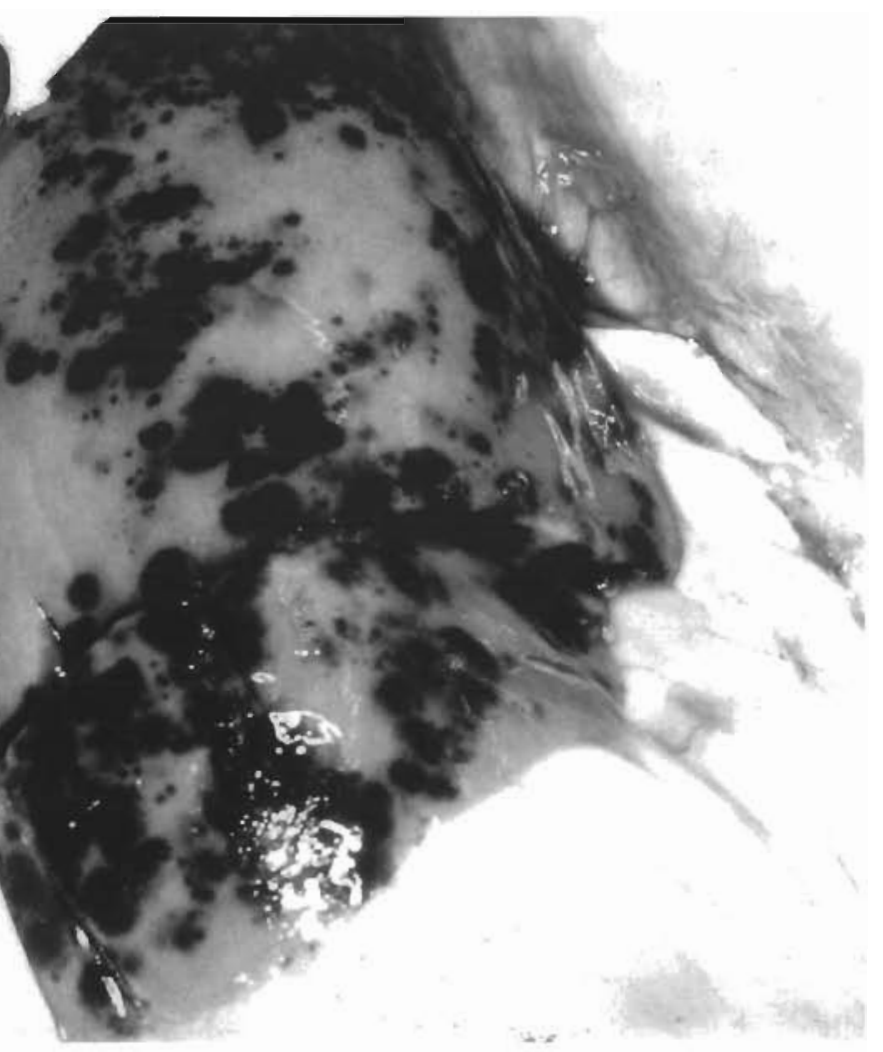




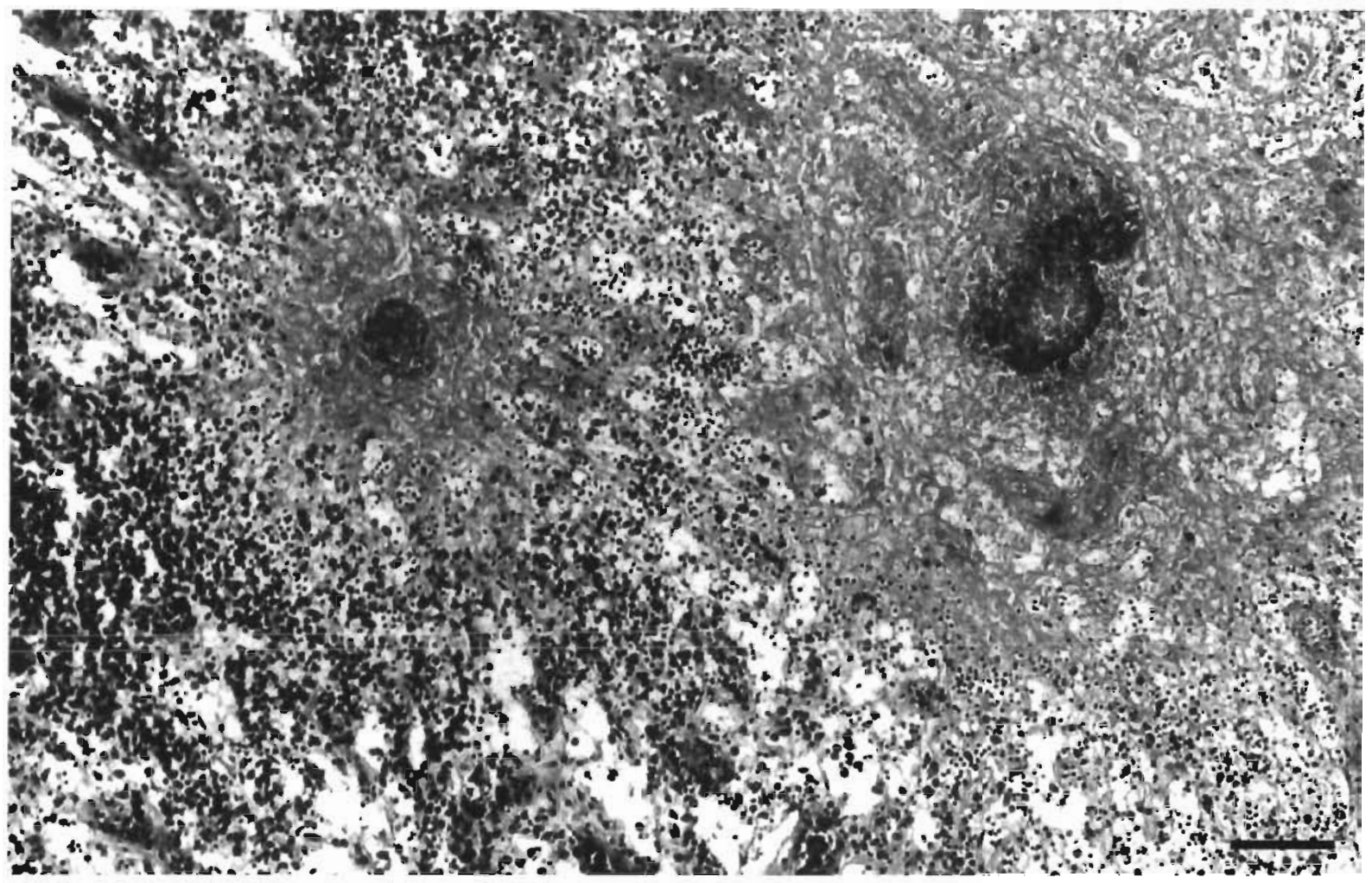

Fig. 3. Central focus of Vibrio viscosus with a diffusing, widespread necrosis and congestion in the spleen. Natural infection. H\&E stain. Scale bar $=100 \mu \mathrm{m}$

erythrophagocytosis (Fig. 3). This was not as marked in the experimental fish. Necrosis of the glomeruli and tubule degeneration were evident in the kidney with scattered hypertrophic, binucleate cells. The gill lamellae were hyperplastic with mild to severe epithelial sloughing. A slight loss of structure to the ventricle was noted. Sections prepared from laboratory-infected fish showed similar lesions.

\section{Bacteriology}

Pure cultures of a Vibrio sp. were isolated from farmed and laboratory-infected Atlantic salmon after 4 to $9 \mathrm{~d}$ on $\mathrm{TSA}+\mathrm{NaCl}$, TSA $+\mathrm{NaCl}$ horse blood and $\mathrm{A} \& \mathrm{O}$ at $15^{\circ} \mathrm{C}$. Short, curved, Gram-negative staining rods were recorded. On $\mathrm{TSA}+\mathrm{NaCl}$ colonies were translucent, creamy yellow in appearance and viscous when touched with a loop, forming long threads when lifted from the medium surface. Haemolysis was recorded and motility evident from slope cultures. All bacterial isolates were fermentative, and oxidase and catalase positive. Full biochemical properties of 1 field and laboratory-recovered isolates are reported in Table 1. The Vibrio cultures were sensitive to amoxycillin, oxolinic acid, oxytetracycline and the vibriostat agent $0 / 129$, with intermediate sensitivity to cotrimoxazole. Cultures isolated from the farmed Atlantic salmon and those from laboratory-infected fish were identical, thus completing Koch's postulates, and were identified as the bacterium $V$. viscosus (Lunder 1992) using the biochemical characteristics presented in Table 1. The key biochemical properties that enabled Vibrio viscosus to be distinguished from $V$. anguillarum and $V$. salmonicida were a positive lysine decarboxylase, and negative citrate, mannitol and sucrose reactions. In addition, no agglutination with $V$. anguillarum or $V$. salmonicida Bionor Mono reagents was recorded. Representative cultures were freeze-dried and isolates MT 1887 and 1896 deposited with the National Collection of Industrial and Marine Bacteria Ltd (NCIMB, Aberdeen, Scotland) as 13484 and 13485.

\section{DISCUSSION}

The condition 'winter ulcers' first emerged $18 \mathrm{yr}$ ago in marine aquaculture in Norway and has been known under this name since the 1990s (Salte et al. 1994). In the present study a Vibrio sp. was isolated in pure culture following an investigation of rising mortality at low water temperatures from moribund 
Table 1. Biochemical characteristics of 'Vibrio viscosus' strains (MT 1887, 1896) isolated from farmed Atlantic salmon Salmo salar using kits from bioMérieux. Results recorded at $15^{\circ} \mathrm{C}$ after $72 \mathrm{~h}$ incubation

\begin{tabular}{|c|c|c|c|}
\hline \multicolumn{2}{|l|}{ API $20 \mathrm{E}$ reactions } & \multicolumn{2}{|l|}{ API $50 \mathrm{CH}$ reactions } \\
\hline Beta-galactosidase & -ve & Glycerol & $-v e$ \\
\hline Arginine dihydrolase & -ve & Erythritol & $-v e$ \\
\hline Lysine decarboxylase & +ve & D-arabinose & $-v \epsilon$ \\
\hline Ornithine decarboxylase & $-\mathrm{ve}$ & L-arabinose & $-v \epsilon$ \\
\hline Citrate & $-v e$ & Ribose & tve \\
\hline $\mathrm{H}_{2} \mathrm{~S}$ & -ve & D-xylose & $-v e$ \\
\hline Urease & -ve & L-xylose & $-v e$ \\
\hline Tryptophane desaminase & -ve & Adonitol & $-v e$ \\
\hline Indole & $-v e$ & $\beta$-methyl-d-xyloside & $-v e$ \\
\hline VP & -ve & Galactose & $-v e$ \\
\hline Gelatinase & /-ve & D-glucose & +ve \\
\hline Glucose & tve & $D$-fructose & tve \\
\hline Annitol & -ve & D-mannose & $-v e$ \\
\hline Inositol & $-\mathrm{ve}$ & L-sorbose & $-v \epsilon$ \\
\hline Sorbitol & - ve & Rhamnose & $-v e$ \\
\hline Rhamnose & -ve & Dulcitol & $-v e$ \\
\hline Sucrose & $-v e$ & Inositol & $-v e$ \\
\hline Melibiose & - ve & Manitol & $-v e$ \\
\hline Amygdalin & $-v e$ & Sorbital & -ve \\
\hline Arabinose & $-v e$ & $\alpha$-methyl-d-mannoside & $-v e$ \\
\hline Oxidase & +ve & $\alpha$-methyl-d-glucoside & $-v e$ \\
\hline $\mathrm{NO}_{2}$ & +ve & $\mathrm{N}$-acetyl-glucosamine & $+v e$ \\
\hline $\mathrm{N}_{2}$ & $-\mathrm{ve}$ & Amygdalin & $-v e$ \\
\hline \multirow[t]{26}{*}{ Motility } & +ve & Arbutin & $-v e$ \\
\hline & & Esculin & -ve \\
\hline & & Salicin & $-v e$ \\
\hline & & Cellobiose & $-v e$ \\
\hline & & Maltose & +ve \\
\hline & & Lactose & $-v e$ \\
\hline & & Melibiose & $-v e$ \\
\hline & & Sucrose & $-v e$ \\
\hline & & Trehalose & $-v e$ \\
\hline & & Inulin & $-v e$ \\
\hline & & Melezitose & -ve \\
\hline & & Raffinose & $-v e$ \\
\hline & & Starch & +ve \\
\hline & & Glycogen & +ve \\
\hline & & Xylitol & $-v e$ \\
\hline & & Gentiobiose & $-v e$ \\
\hline & & D-turanose & $-v e$ \\
\hline & & D-lyxose & $-v e$ \\
\hline & & D-tagatose & $-v e$ \\
\hline & & D-fucose & $-v e$ \\
\hline & & L-fucose & $-v e$ \\
\hline & & D-arabitol & $-v e$ \\
\hline & & L-arabitol & -ve \\
\hline & & Gluconate & $-v e$ \\
\hline & & 2-keto-gluconate & +ve \\
\hline & & 5-keto-gluconate & $-v e$ \\
\hline
\end{tabular}

infection. However, both Lunder (1992) and Lunder et al. (1995) demonstrated that the bacterium named $V$. viscosus was the causative agent. In the current study the ecchymotic, diffuse blackening of the liver and the biochemical profile of the bacterial isolates were sufficient to conclude that the disease outbreak in the Shetland Isles, Scotland was similar to that recorded by Lunder et al. (1995) in Norway. Key biochemical properties were also established enabling $V$. viscosus to be distinguished from other pathogenic marine Vibrio spp. recorded from farmed salmonids. This report extends the known range of winter ulcers from Norway and Iceland to include the Shetland Isles. Interestingly, the report by Cox et al. (1986) of a new Aeromonas sp. might conceivably represent an earlier finding of $V$. viscosus in Scotland as the biochemical properties they described were similar to those noted in the current study.

The infection of laboratory-reared Atlantic salmon with a farm isolate of Vibrio viscosus resulted in similar, although fewer prominent gross signs in the moribund fish. The dark ecchymotic areas associated with the liver from moribund farmed fish may be regarded as a feature of winter ulcer disease. The gross liver lesions were distinct from the dark, black livers reported for the viral infection causing infectious salmon anaemia (ISA) in Norway (Evensen et al. 1991) and mainland Scotland (Rodger et al. 1998). The circular or oval, epidermal ulcers were a feature of moribund farmed and laboratory-infected salmon and these appeared to develop through the simple loss of the epithelium, which exposed the underlying tissue. The histological description of the muscle lesions given by Lunder (1992) corresponds with that recorded in the present study. As the affected population were all harvest-sized fish the presence of such lesions would result in a down-grade in quality.

farmed Atlantic salmon Salmo salar. The biochemical properties of the bacterium corresponded with those described for a novel Vibrio sp. by Lunder (1992) with the proposed name Vibrio viscosus, and the Vibrio sp. reported by Lunder et al. (1995), both isolated from farmed Atlantic salmon. Work by Salte et al. (1994) provided plausible causes for the outbreaks of the condition termed winter ulcers in farmed salmon and they postulated a role for dietary iron in the thrombotic process with an opportunistic role for a bacterial
Lunder et al. (1995) reported mortality of less than $10 \%$ in an outbreak, although in some cases up to $50 \%$ of the population might be affected at slaughter (Lunder 1992). In the current study, total fish losses amounted to $2.5 \%$ in $4 \mathrm{mo}$, although higher losses were noted in the laboratory-infected fish.

Emerging disease problems in aquaculture often require periods of research before an infective agent can be identified. For example, the causative agent of cold water vibriosis, Vibrio salmonicida, was not iden- 
tified until the work of Egidius et al. (1986), although outbreaks had persisted in Norwegian salmonid culture since the late 1970s (Egidius et al. 1981). Hence, characterization, or the recognition of the proposed name, Vibrio viscosus, is required. Furthermore, it is also necessary to establish the role of other Vibrio spp. from marine waters connected with winter ulcer diseases of farmed Atlantic salmon, particularly the 'cold water' Vibrio spp. isolated by Lunder (1992) and Benediktsdóttir et al. (1998).

Acknowledgements. The authors thank C. Mitchell and B. Wood for help with collecting the field samples.

\section{LITERATURE CITED}

Benediksdóttir E, Helgason S (1997) Challenge of Atlantic salmon parr with different strains of $V$. viscosus. VIII International Conference of the European Association of Fish Pathologists 'Diseases of Fish and Shellfish', Edinburgh, $14-19$ September, p 154

Benediksdóttir E, Verdonck L, Swings J (1997) Characterization of Vibrio viscosus strains isolated at different geographical locations. VIII International Conference of the European Association of Fish Pathologists 'Diseases of Fish and Shellfish', Edinburgh, 14-19 September, p 169

Benediktsdóttir $E_{1}$ Helgason S, Sigurjónsdóttir H (1998) Vibrio spp. isolated from salmonids with shallow skin lesions and reared at low temperature. J Fish Dis 21:19-28

Bruno DW, Hastings TS, Ellis AE (1986) Histopathology, bacteriology and experimental transmission of a cold water

Editorial responsibility: Managing Editor vibriosis in Atlantic salmon Salmo salar. Dis Aquat Org 3 $163-168$

Cox Dl, Morrison DJ, Rae GH (1986) Report on a new Aeromonas species infecting skin lesions of Atlantic salmon (Salmo salar L.) in sea water. Bull Eur Assoc Fish Pathol 6:100-101

Egidius E, Andersen K, Clausen E, Raa J (1981) Cold-water vibriosis or 'Hitra disease' in Norwegian salmonid farming. J Fish Dis 4:353-354

Egidius E, Wiik R, Andersen K, Hoff KA, Hjeltnes B (1986) Vibrio salmonicida sp. nov., a new fish pathogen. Int J Syst Bact 36:518-520

Evensen $\varnothing$, Thorud KE, Olsen YA (1991) A morphological study of the gross and light microscopic lesions of infectious salmon anaemia in Atlantic salmon (Salmo salar). Res Vet Sci 51:215-222

Lorenzen $E$ (1993) The importance of the brand of the beef extract in relation to the growth of Flexibacter psychrophilus in Anacker \& Ordal's medium. Bull Eur Assoc Fish Pathol 13:64-65

Lunder T (1992) 'Winter ulcer' in Atlantic salmon. A study of pathological changes, transmissibility, and bacterial isoiates. PhD thesis, The Norwegian College of Veterinary Medicine, Oslo

Lunder T, Evensen Ø, Holstad G, Håstein T (1995) 'Winter ulcer' in the Atlantic salmon Salmo salar. Pathological and bacteriological investigations and transmission experiments. Dis Aquat Org 23:39-49

Rodger HD, Turnbull T, Muir F, Millar S, Richards RH (1998) Infectious salmon anaemia (ISA) in the United Kingdom. Bull Eur Assoc Fish Pathol 18:115-116

Salte R, Rørvik KA, Reed E, Norberg K (1994) Winter ulcers of the skin in Atlantic salmon, Salmo salar L., pathogenesis and possible aetiology. J Fish Dis 17:661-665

Toranzo AE, Barja JL (1993) Virulence factors of bacteria pathogenic for coldwater fish. Annu Rev Fish Dis 3:5-36

Submitted: May 28, 1998; Accepted: August 25, 1998

Proofs received from author(s): October 7,1998 